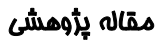

\section{بررسى ميزان ياسخ ايمنى واكسن هياتيت B در دانشجويان دختر دانشكاه علوم

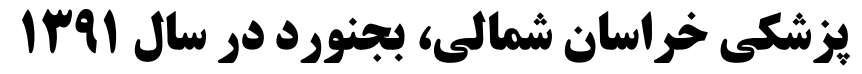

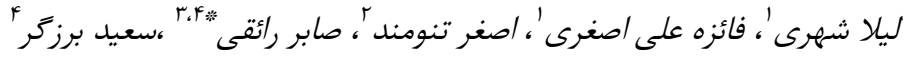

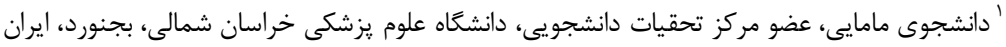

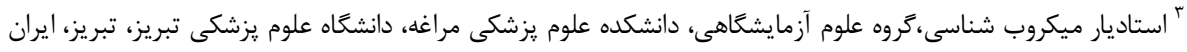

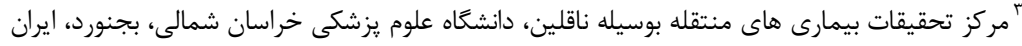

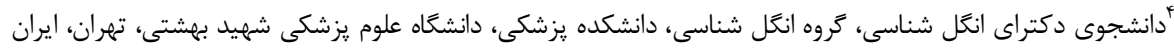

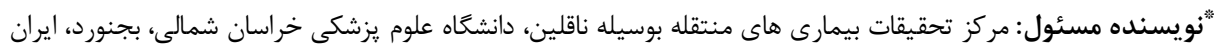 \\ بِ
}

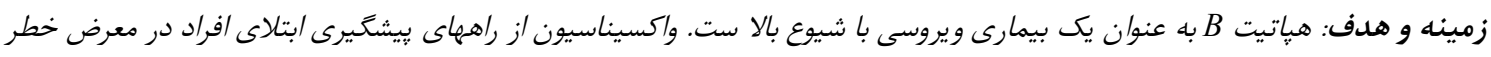

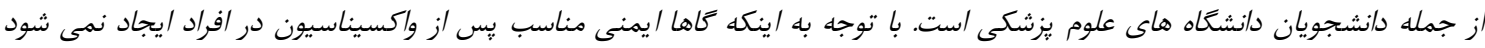

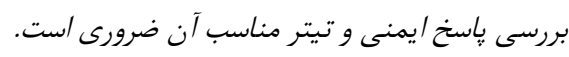

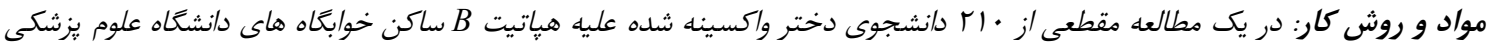

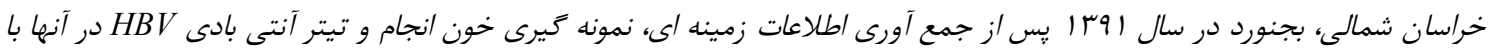

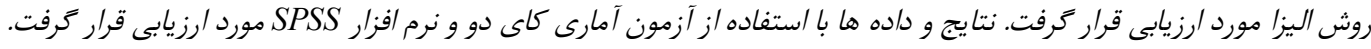

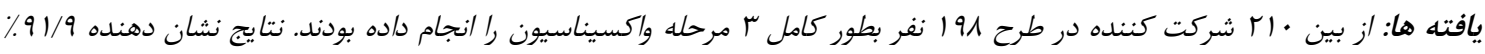

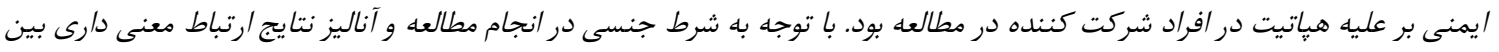

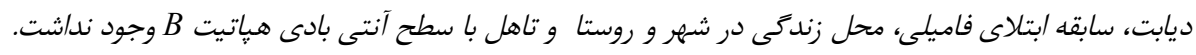

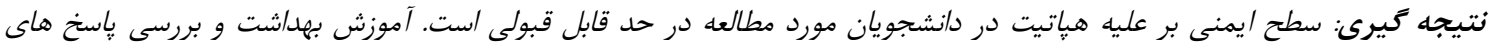

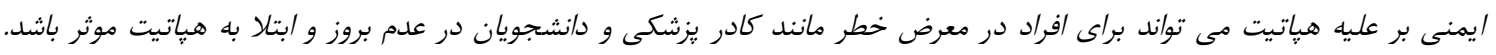

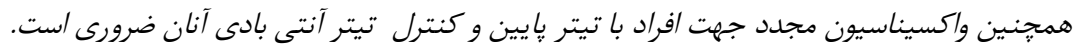
وازه هاى كليدى : هياتيت، دانشجويان، آنتى بادى مجنى

هياتيت B به تنهايى مهمترين علت بيمارى كبدى و اصلى إنى مقدمه

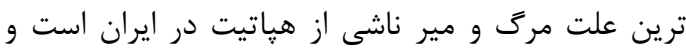
بيمارى هياتيت B در تمام جهان وجود داشته و بيش از

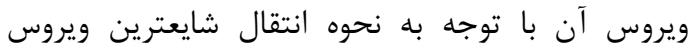

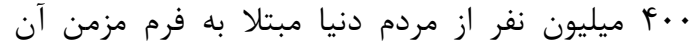

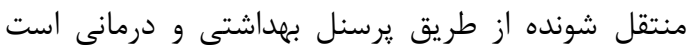

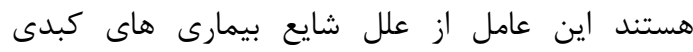

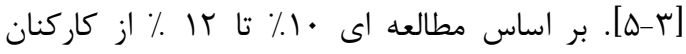

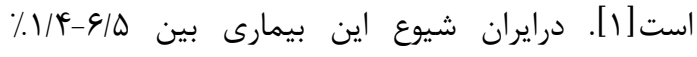

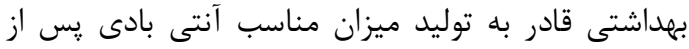

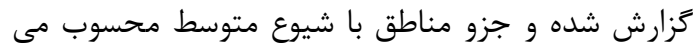
تزريق واكسن نبوده و عوامل متعدد در ميزان تاثير واكسن

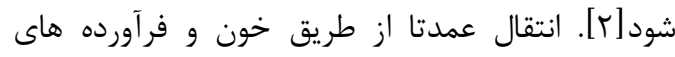
هياتيت B از جمله شيوع عفونت، سن، جنس، وزن،

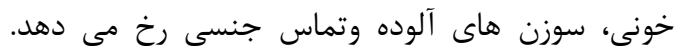


(بجنورد) در سال |qس| كه قبل از ورود به دانشخاه بر عليه هياتيت B واكسينه شده بودند، انجام شد. پس از ارائه توضيحات توسط محققين و با توجه به شناخت نحوه انتقال

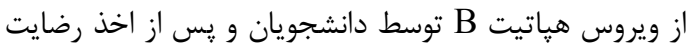
نامه كتبى و اطمينان از محرمانه بودن اطلاعات و نتايج،

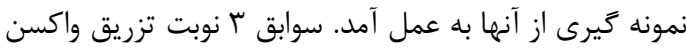
هياتيت، فرو رفتن سوزن تزريقى در بيمارستان، تاهل،

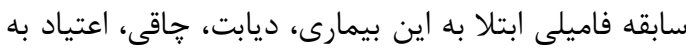

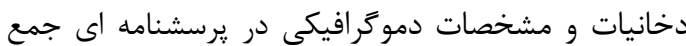
آورى شد. پس از تكميل فرم يرسشنامه از هر فرد ب ميلى ليتر خون تهيه و سرم تمام نمونه ها بلافاصله جدا و در

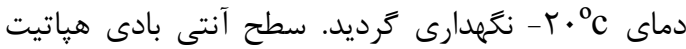
شركت كنند Biotech Company® مورد بررسى قرار كرفت. نتايج بدست آمده با استفاده از نرم افزار SPSS و آزمون هاى فيشر و كاى- اسكوير تجزيه و تحليل و سطح ه • • • p معنى دار تلقى شد.

يافته ها

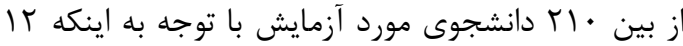
نفر از آنها دوره سه كانه واكسينايون را به اتمام نرسانده بودند از مطالعه خارج شدند. ميانگين سنى شركت رته كنند دانشجويان مورد مطالعه در نمودار شماره ا نشان داده
ساختار زنتيكى و فيزيولوزيكى فرد، اعتياد به سيغار، تفاوت ساختارى واكسن، مدت زمان سيرى شده از آخرين دز تزريقى و تماس با فرد آلوده در محيط دخالت دارد

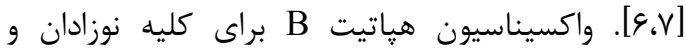
اطفال و بالغين جوان و كادر بهداشت و درمان توصيه شده و در ايران انجام مى يذيرد. تزريق بانوبت واكسن در ه9. از اطفال و • 9\% از بالغين ايجاد آنتى بادى كافى كافى مى كنى كند

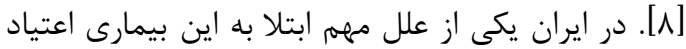
تزريقى است و در كادر يزشكى فرو رفتن سوزن آلوده،

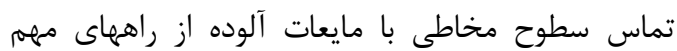

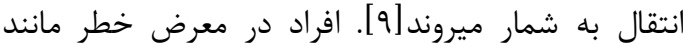
دانشجويان دانشگاه هاى علوم يزشكى بطور مستقيم و غير

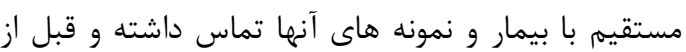
ورود به محيط بهداشت و درمان بايد از گِاسخ ايمنى مناسب بر عليه هياتيت در بدن خود مطمئن باشند. در

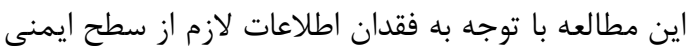

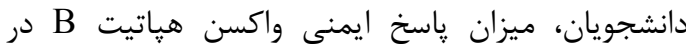
دانشجويان دختر ساكن خوابگاه هاى دانشعاه علوم يزشكى خراسان شمالى، بجنورد در سال اوسا مورد بررسى و تجزيه و تحليل قرار گرفته است. بحتئ روش كار اين مطالعه مقطعى بر روى • ال دانشجوى دختر ساكن

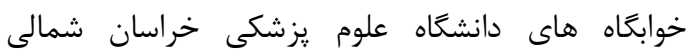

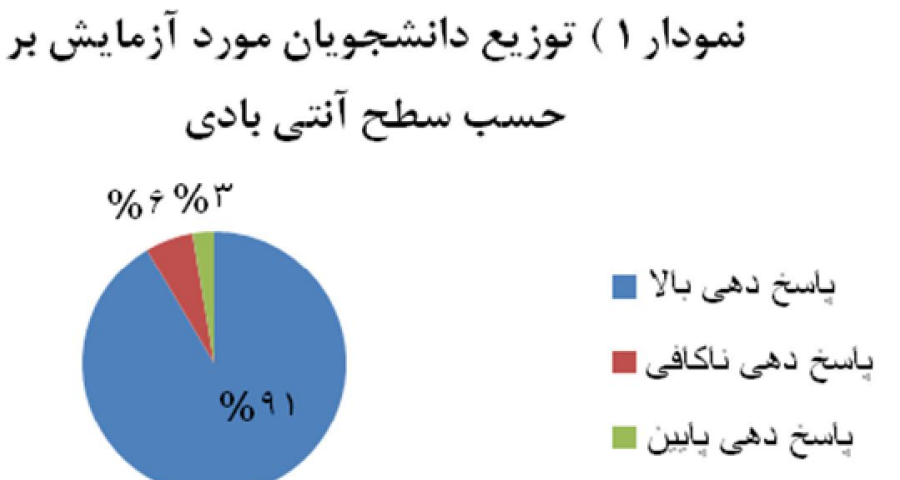


مى شود[با]. همجنين سطح ايمنى بالا در دختران

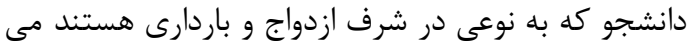

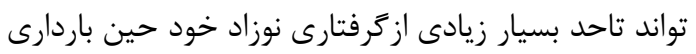

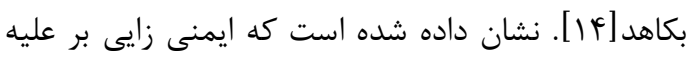

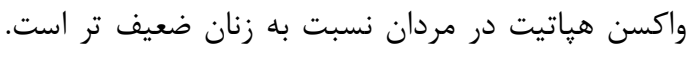

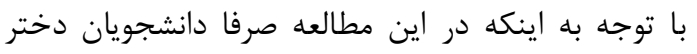

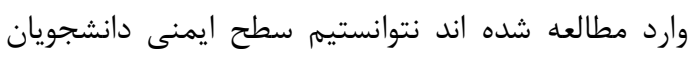

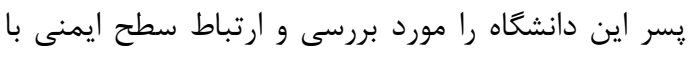

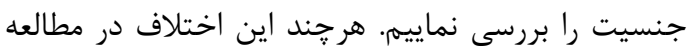

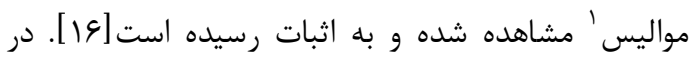
تحقيق حاضر هيج رابطه معنى دارى بين ديابت، وضعيت

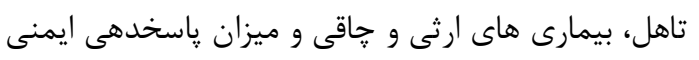
به واكسن هياتيت وجود نداشت كه شايد علت اين مسئله، رئل يايين بودن متوسط سن شركت كنند زمينه اى مورد مطالعه در جمعيت جوان مي بـ باشد. به طور كلى به نظر مى رسد واكسن هياتيت B در مر ايران به موله خوبى توانسته است در ايمنى زايى افراد موفق عمل نمايد.

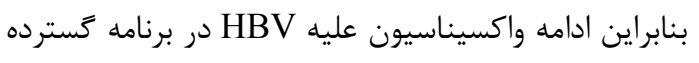

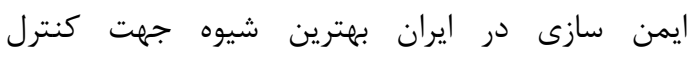

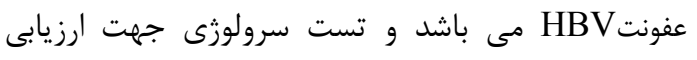

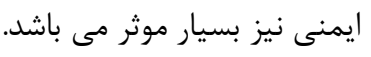

نتيجه كيرى

سطح ايمنى بر عليه هياتيت در دانشجويان مورد مطالعه

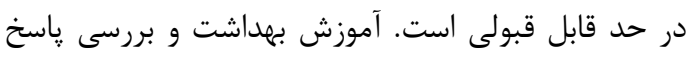

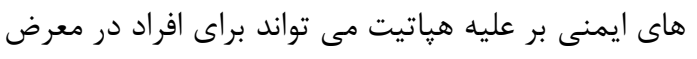

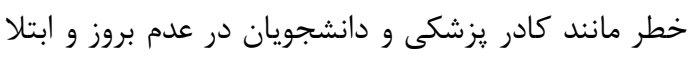

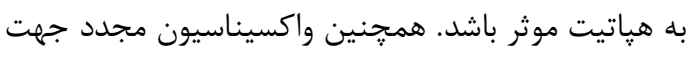

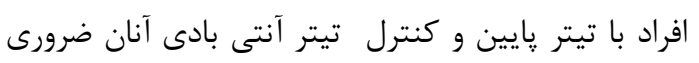

\section{تشكر و قدردانى}

اين مطالعه بطور كلى با حمايت مالى و معنوى معلى معاونت

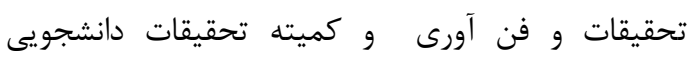

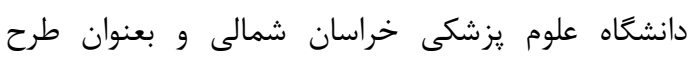

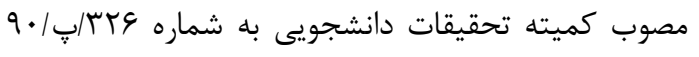

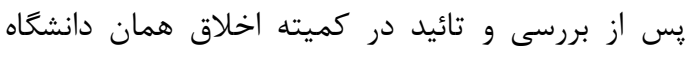

1 -Moralis
شده است. از بين • •ا دانشجو نمونه كيرى انجام شد

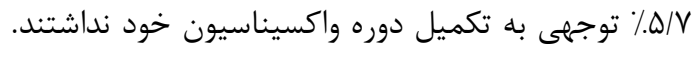

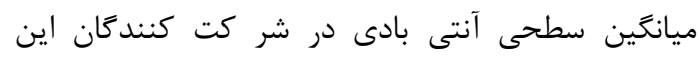
طرح \&\&/4 ليتر بود. با توجه به شرط جنسى در انجام مطالعه و آناليز

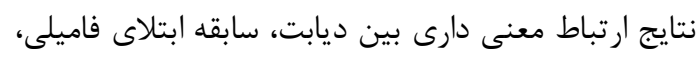

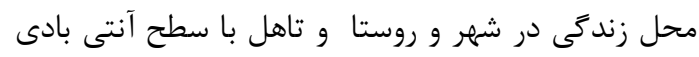

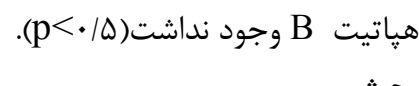

أو ٪ از دانشجويان واكسينه شده دختر ساكن خوابكاه

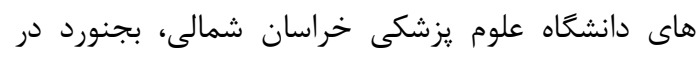

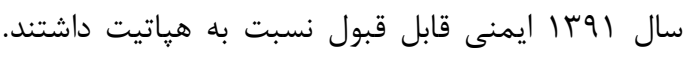

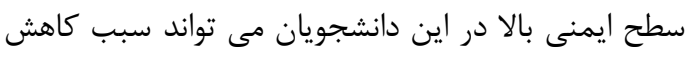
موراد آلودىى اين دانشجويان در محيط كار دار به دئ هياتيت

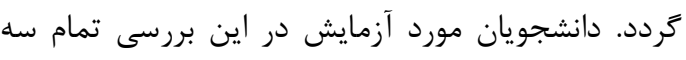

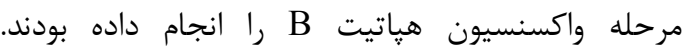

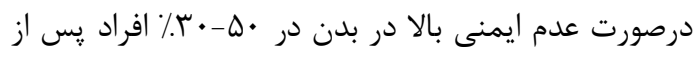

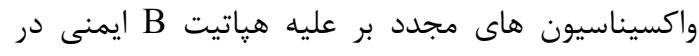

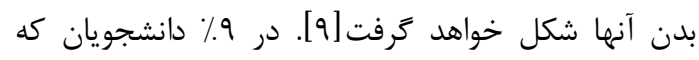

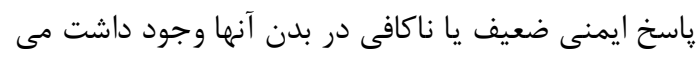

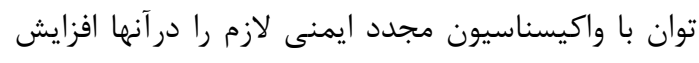

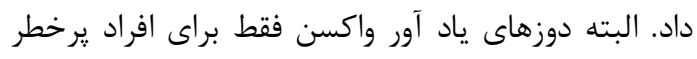

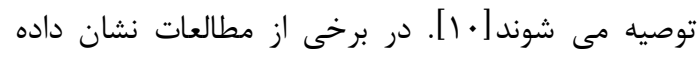

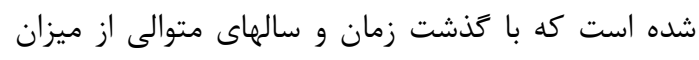

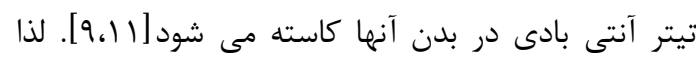

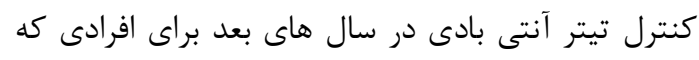

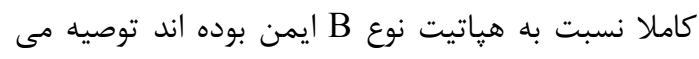

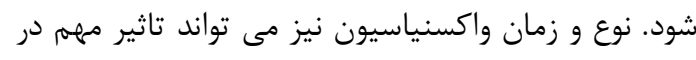

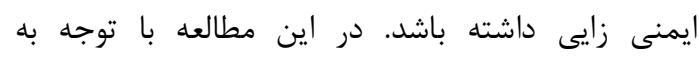

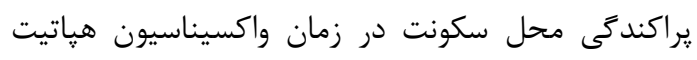

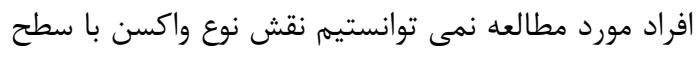

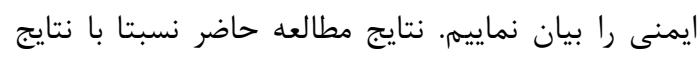

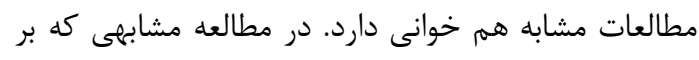

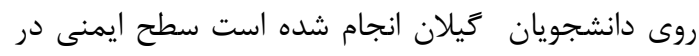

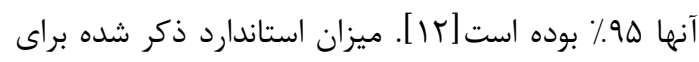

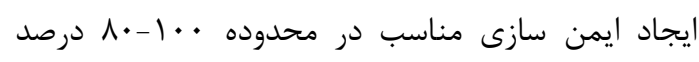

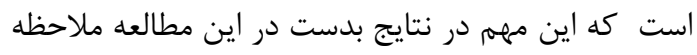


انجام گرفته است. نويسندكان از دانشجويان شركت كننده

$$
\text { در اين طرح كمال تشكر را دارد. }
$$

\section{References}

1. Zuckerman JN, Zuckerman AJ, The epidemiology of hepatitis B, Clin liver Dis 1999;3:179-87.

2. Nabipour Iraj, Hepatitis virus in Iran, Tebe Jonoub 1999:56-59.

3. Noppornpanth S, Sathirapongsasuti N, Chongrisawat V, Poovorawan V, Detection of HBs Ag and HBV DNA in serum and Saliva if HBV carriers, Southeast Asian J Trop Med Public Health 2000; 31(2): 419-21.

4. Alavi Moghaddam M. Hepatitis A virus: a major global public health problem, especially in developing countries. Hepat Mon 2005; 5:145-9.

5. Moran GJ, Emerhancy Department management of blood and body fluid exposures, Ann Emerg Med 2000;35(1) : 4262 .

6. Alavian SM, Hajarizadeh B, Ahmadzad-Asl M, Kabir A, BagheriLankarani K, Hepatitis B virus infection in Iran: a systematic review, Hepat Mon 2008; 8:281-94.

7. Louther J , Feldman J, Rivera P ,Hepatitis B vaccination program at a New York City hospital: seroprevalence, seroconversion, and declination, Am J infect control 1998 ;26(4):423-7.

8. Kahn J. Preventing hepatitis A and hepatitis

$B$ virus infections among men who have sex with men, Clin nfect Dis 2002; 35: 1382-7.
9. De Vries B, Cossart YE, Needlestick injury in medical students, Med J Aust 1994; 160: $398-400$.

10. Van der Sande MA, Waight P, Mendy M, Rayco-Solon P, Hutt P, Fulford T et al, Longterm protection against carriage of hepatitis $B$ virus after infant vaccination, $J$ Infect Dis 2006; 193:1528-35.

11.Poland GA,Shefer AM,McCauley M, et. al. Standards for Adult Immunization Practices, American Journal of Preventive Medicine 2003; 25(2): 144-150.

12.Mansur-Ghanaei F, Fallah MS,HBV vaccination in Guilan, The northern province of Iran; sufficient or not?, Iranian Journal of Infectious Diseases 2008;040:47-53.(persion)

13.Centers for Disease Control and Prevention, Hepatitis B and Hepatitis B vaccine, Epidemiology and Prevention of Vaccine-Preventable Disease , Revised December 2003 , Available at : www.cdc.gov/nip .

14.Euler GL, Copeland JR, Rangel MC, Williams WW, Antibody response to postexposure prophylaxis in infants born to hepatitis B surface antigen- positive women, Pediatr Infect Dis J 2003; 22: 123-9.

15. Morales J, Analytical review of the response by sex to vaccination against hepatitis B in hospital personnel.Aten primaria, 1993; 12(2):99-101. 
Original Article

\title{
Evaluation of immune response against hepatitis $B$ vaccine in North Khorasan University of Medical Sciences female students,Bojnurd in 2013
}

\author{
Shahri L ${ }^{l}$, Ali-asghari $F^{l}$, Tanomand Asghar ${ }^{2}$, Reaghi Saber ${ }^{3,4^{*}}$, Barzegar Saeid $^{4}$ \\ ${ }^{1}$ Midwifery student, North Khorasan University of Medical Sciences,Bojnurd, Iran \\ ${ }^{2}$ Assistant Professor, Dept. of Laboratory Sciences, Maragheh Faculty of Medical Sciences, Tabriz university of \\ Medical Sciences, Tabriz, Iran \\ ${ }^{3}$ Vector- borne Diseases Research Center, North Khorasan University of Medical Sciences, Bojnurd, Iran \\ ${ }^{4} \mathrm{PhD}$ candidate of Parasitology,Parasitology Department, Medical Faculty, Shahid Beheshti University of \\ Medical Science, Tehran, Iran
}

\begin{abstract}
*Corresponding Author: School of Medicine \& Vectorborne Diseases Research Center , North Khorasan University of Medical Sciences, Bojnurd, Iran Email:saberraeghi@gmail.com
\end{abstract}

\begin{abstract}
Background \& objectives: Hepatitis $B$ is a viral disease with high prevalence. .Vaccination of at risk persons like medical students will preven of infection. Unfortunately immunologic response to the vaccines is not perfect sometimes and it is necessary to examine the immune response.
\end{abstract}

Materials \&Methods: In a cross-sectional study of 210 female students that have been vaccinated against hepatitis $B$ at the dormitories of North Khorasan University of Medical Sciences ,Bojnurd in 2013. After collecting demographic data, sampling of blood was done and antibody titer $H B V$ was assessed by ELISA. Data were analyzed by SPSS software and presented with chi-square test.

Results : Among 210 participants, 198 completed the 3 stages of vaccination against $H B V$ and $91.9 \%$ of participating in the study had adequate response against hepatitis. Also, there were no significant correlation between the immunity response, diabetes, family history, living in urban or rural and marriage condition.

Conclusion: In this study immunity against hepatitis was in acceptable level. Health education and evaluation of immune responses against hepatitis in medical staff and students is very effective. Also revaccination for persons with low titers of antibody is essential.

Keywords: Hepatitis, HBV, students, Bojnurd, antibodies 